\title{
Jamie Cross, Simone Abram, Mike Anusas and Lea Schick (eds) (2017) Our Lives with Electric Things. Theorizing the Contemporary, Fieldsights, December 19, 2017. Society for Cultural Anthropology. https://culanth.org/fieldsights/series/our-lives-with-electric-things
}

\author{
Elaine Gan \\ elaine.gan@nyu.edu
}

"Our Lives with Electric Things" was published online in December 2017 as part of Fieldsights' wonderfully experimental series called Theorizing the Contemporary. Growing out of earlier workshops on "Electrifying Anthropology" sponsored by the Wenner-Gren Foundation and convened at the University of Durham and ITU Copenhagen, the published collection is large (relative to other Fieldsights sections), with 51 entries organized into 17 groups of three. The entries follow a more or less uniform template and the collection as a whole reads like a catalog (a term used by the editors) or a social media feed: each entry represents a specific 'electric thing' with a short descriptive title (e.g., Gould's "Electric Candles", Badami's "Flatpack Sunlight", Angelini's "Overcharged" to name a few of my favorites); a single color photograph or illustration; and about 300 words written as first person anecdote by an anthropologist or STS/media theorist (which I discuss further below). This is a smart editorial decision. The simple uniformity and brevity of entries allow the heterogeneity and groundedness of the individual lenses and voices to shine. The familiar becomes strange, and the strange familiar - one of the most generative contributions of anthropology as a discipline.

Kudos to editors Jamie Cross, Simone Abram, Mike Anusas, and Lea Schick, for a refreshing assemblage of images, writing styles, and subjects. The entries are insightful and accessible - a good model for the use of digital media over print. The photographs are visually compelling; given room to breathe on a webpage and appearing in full color, the images work as intimate portraits of concrete things, as well as portals into everyday practices unfolding in multiple worlds. A variety of genres are represented: from tight close-ups like Ted Gordon's electric music box and wonderful domestic still lifes like Pamila Gupta's air conditioner, to landscape photos like Erin Parish's aerial view of La Chorrera waterfalls in Puerto Rico, action photos like Matthäus Rest removing curd from a vat at an alpine dairy in Switzerland, and great stolen shots like Barbara Carbon's framing of two mechanics in a dark Congolese hydroelectric plant. Photo captions and credits are precious, acting as small registers of a particular moment in a particular place lived by particular someones. (I do wonder why dates were left out - an oversight that rarely happens in documentary projects. Although the information likely exists in each photo's metadata, noting the date of capture is crucial in field-based work). The writing styles and genres range from diaristic prose to thick description, ethnographic and historical to poetic and speculative, personal to political and theoretical. Readers get to follow their curiosities and scroll through entries in no particular sequence. A few contributors use the format exceptionally well, experimenting with alternatives to long-form academic journal writing and more open approaches to analysis. In 
"Accra Beauty Blue", Pauline Destree offers a poetic rendition of multiple affective registers of blue light in Ghana, technologies of desire that she calls "beauty blue". Trisha Phippard examines an ambivalent "human relationship to electrons" by writing about the technological promise as well as precarity that accompanies the arrival of a new $x$-ray machine in a hospital in a Congolese town of "1.2 million with no main-line electricity." On a different continent, Trang X. Ta is situated in the Sham Shui Po district of Hong Kong, where new and old devices and appliances are sold alongside heaps of remote controls "separated from their main components" and offered in a secondhand street market for discarded and obsolete electric things. Meanwhile, the highest concentration of wind turbines in the United Kingdom churn away in the Orkney islands to deliver power and electric futures to households that live in the highest levels of "fuel poverty" in Scotland; Rebecca Ford writes about Orkney electricity that is "both abundant and unaffordable," a local and global entanglement of markets, energy, and power.

By curating various things together, the editors aim to convey the seeming ubiquity of electricity, to make visible invisible currents that run through and organize contemporary life. Since the nineteenth century, with Thomas Edison's incandescent light bulb and electric utility company in Newark and then later George Westinghouse's alternating current system in Pittsburgh, electricity has been central to the making of colonial and modern forms of life, knowledge, wealth, and power around the world. But access to electricity has been violently uneven and historically contingent. In their introduction, the editors pose a rhetorical question: "Can we still imagine the possibility of lives without electric things?" This immediately begs a question that is being raised increasingly, in the humanities and social sciences, yet not enough: Who is this imagined 'we'? As noted earlier, the collection is curated into 17 sections, all of which begin with the possessive "Our". Thus, the sections begin with "Our Body Electric", "Our Electric Air", "Our Electric Backup", and so forth, until the final "Our Electro-Homes". Whose lives are referenced by the title, "Our Lives with Electric Things"? "Our Lives" implies universality but the entries argue against precisely that.
The collection is neither an exhaustive catalog (cars and other vehicles, computers, and even cameras, for example, are strikingly absent) nor representative of a single common body or standpoint. There is no 'we'; there is no 'our'.

The collection offers what Donna Haraway (1988: 582-583) calls 'situated knowledge', by which she means a feminist objectivity that "turns out to be about particular and specific embodiment and definitely not about the false vision of transcendence of all limits and responsibility... It allows us to become answerable for what we learn how to see". This, to me, is the project's key contribution and it is left unexamined. The contributors write from their particular locations, offering partial perspectives from - not of worlds otherwise. As a member of the Karrabing Film Collective in northern territories of Australia, Elizabeth Povinelli (2016) collaborates on short videos (captured with handheld cameras and smartphones) that she describes as "improvisational struggles" within settler late liberalism or modes of "governance of difference and markets" that emerged in the 1960s. Rather than representations of indigeneity and colonial occupation, the Karrabing videos are enactments of what contemporary life is and can be from the perspectives of the dispossessed or again, what Haraway calls 'subjugated standpoints.' The diversity and scope of the collection powerfully suggest this kind of feminist politics at its heart, or its various hearts. Unfortunately, the editors miss the opportunity to take its pulse or at least point to its possibilities.

Instead, the aim of the collection is to "extend anthropology's contribution to the new energy humanities" and the editors hope to "electrify anthropology, and inspire a generation of anthropologists to think electric". "Our Lives", in this sense, means anthropologists' lives. Should the project be read as a collection by anthropologists and for anthropologists exclusively? I don't think this is what the editors intend. The energy humanities is an emerging field led by Cymene Howe and Dominic Boyer and Imre Szeman (2014) who argue for interdisciplinary approaches to the "energy dilemmas" of the Anthropocene, a highly debated umbrella term that tries to broadly describe a novel geological epoch dominated by humans and particularly industrialized capitalism. 
I see how paying attention to electric things as artefacts and as material-semiotic practices enables consideration of various mechanisms of the Anthropocene in ways that other kinds of things might not. In a section titled "Our Electric Meters," Moyukh Chatterjee writes of illegal electricity meters in their building in Delhi as collective forms of agency that connect to and get cut off from the state, literally. Electricity is political. Playing off Foucault's (1976) concept of sovereign power, Chatterjee writes: "Faulty meters, red tape, and arbitrary meter readings transformed state officials into little sovereigns with the ability to give power or deny light". In the same section, Antina Von Schnitzler plays off Latourian sociality by describing electric meters in Kenya as instruments of measurement that are performative, "a material-semiotic practice that produces realities, rather than merely representing them". Then there are flows and transformations of energy that rethink the personal and the political across history and scale. Jonathan Devore's "Watermill" in a section called "Our Electric Exchanges" is about a homemade hydroelectric watermill in Bahia, Brazil that is used to charge an old battery which lights a bulb for a landless rural family. Devore connects the lightbulb to the Brazilian state's rural electrification initiatives and unevenly distributed electrical grids. In these entries, electricity not only illuminates but mediates power and agency, creating and disrupting affordances, enacting the art and science of governing and not being governed. Indeed, "electric things are good to think with" as the editors write. Following electricity from multiple perspectives articulates how the Anthropocene is not a foregone conclusion but a complex of situated everyday practices through which matter and energy are constantly being transformed. This is another contribution worthy of editorial comment.

My last point inquires after the kinds of methods that may be drawn from ethnographic attention to the polysemic and prosthetic nature of electric things, the multiple meanings, capacities, and relations that are produced at multiple scales when transformations occur in both expected and unexpected ways (when Phippard's x-ray machine breaks down, for example). Electric things are good to think with because they hold kinetic and potential energy; they can be plugged and unplugged; they can become absolutely essential and then quickly obsolete unless they might be rigged, updated or hacked in between. Electric things are methods, experiences, and artefacts, simultaneously: with electric things we make and make do, even as who 'we' might be gets made and unmade through things that range from a screwdriver circuit tester in Lubumbashi (Rahier) to Facebook data centers in Odense (Winthereik), from baraat laltens or celebratory lamps carried by musicians in Uttarakhand (Partridge) to provisional energy infrastructures in the form of floating powerships anchored in Ghana's harbor (Günel).

In 2007, Amiria Henare, Martin Holbraad, and Sari Wastell edited a provocative volume titled Thinking Through Things. They argue for an "artefact-oriented anthropology" that refuses too-quick applications of pre-existing theory to ethnographic material and instead works toward articulating methods through which the material itself draws out theory. They describe their project as methodological, calling on anthropologists to "attend to 'things' as they emerge in diverse ethnographic settings, and to begin such investigations with what, for the ethnographer, may appear as a logical reversal: rather than providing data to which theory is applied, revealing the strengths and flaws of an existing theoretical model, the things encountered in fieldwork are allowed to dictate the terms of their own analysis - including new premises altogether for theory" (Henare et al., 2007: 4). Electric things can electrify anthropology - and more broadly, studies of the messy and unruly entanglements of the Anthropocene - in precisely this way. 


\section{References}

Boyer D and Szeman I (2014) The rise of energy humanities. Available at: https://anthropology.rice.edu/ sites/g/files/bxs1041/f/The\%20Rise\%20of\%20Energy\%20Humanities.pdf (accessed 25.3.2019).

Foucault M (1976) The History of Sexuality Volume 1: An Introduction. Trans. Robert Hurley. New York: Vintage Books.

Haraway D (1988) Situated Knowledges: The Science Question in Feminism and the Privilege of Partial Perspective. Feminist Studies 14(3): 575-599.

Henare A, Holbraad M and Wastell S (2007) Thinking Through Things: Theorising artefacts ethnographically. London and New York: Routledge.

Povinelli E (2016) Geontologies: A Requiem to Late Liberalism. Durham and London: Duke. 